\title{
An Expanding Role for Immunotherapy in Colorectal Cancer
}

\author{
Katherine M. Bever, MD, a,b and Dung T. Le, MD ${ }^{\mathrm{a}, \mathrm{b}}$
}

\begin{abstract}
Colorectal cancer (CRC) is a leading cause of cancer-related mortality in the United States. Response rates to second- and third-line therapy for metastatic CRC ( $\mathrm{mCRC}$ ) remain low, and immunotherapy is an attractive strategy for treatment in these patients given generally better tolerability than conventional chemotherapy and the potential for long-lasting durable responses. In particular, the novel checkpoint inhibitors (CPIs) have demonstrated unprecedented clinical activity in a wide range of cancers. The observation of clinical activity in microsatellite instability-high (MSI-H) mCRC was the first indication of a potential for CRC to respond to these agents, and has led to a breakthrough designation by the FDA for CPI use in this subset. Despite this, a proportion of MSI-H and nearly all microsatellite stable disease will not respond to single-agent checkpoint inhibition, and clinical trials are ongoing to increase responses to immunotherapy in $m C R C$ through both better patient selection and novel combinations of immunotherapeutic agents. This review will provide a focused update on the most compelling clinical results of immunotherapy in CRC to date, as well as a summary of current strategies being tested in clinical trials in increase responses to immunotherapy in CRC.
\end{abstract}

J Natl Compr Canc Netw 2017;15(3):401-410

Colorectal cancer (CRC) is one of the most common cancers in the developed world and is increasing in incidence globally. In the United States, it is the third most common cause of cancer-related mortality in both men and women. ${ }^{1}$ Survival from CRC in the United States appears to be improving within the past 2 decades, ${ }^{2}$ but remains low in metastatic CRC (mCRC), with a 5-year survival rate of approximately $13 \% .^{3}$ Recently approved cytotoxic agents in this setting have yielded marginal benefits. ${ }^{4,5}$

Immunotherapy holds promise as a more targeted, potentially less toxic therapy, and the so-called checkpoint inhibitors (CPIs) have recently received regulatory approval in multiple cancers, including melanoma and lung, kidney, bladder, and head and neck cancers, based on durable clinical responses demonstrated in a subset of patients. However, response rates to these agents were low in unselected patients with CRC. ${ }^{6-8}$ The more recent demonstration of responses in micro-

From the aDepartment of Oncology and 'The Sidney Kimmel Cancer Center, Johns Hopkins University School of Medicine, Baltimore, Maryland.

Submitted October 4, 2016; accepted for publication February 10, 2017.

Dr. Le has disclosed that she receives research funding from Merck and Bristol-Myers Squibb, and speakers honorarium from Merck. Dr. satellite instability-high (MSI-H) CRC to CPIs was a turning point, and has led to several clinical trials and increased efforts to obtain responses in patients with microsatellite stable (MSS) CRC and to identify other predictive biomarkers.

This review provides an update of the activity of immunotherapy in MSI-H CRC and ongoing efforts to increase activity of immunotherapy in MSS CRC through identification of other potentially susceptible subsets of CRC and through novel combination immunotherapies.

\section{MSI is a Biomarker of Response to CPI}

MSI-H CRC results from defective mismatch repair proteins (dMMRs), as seen in hereditary Lynch syndrome and in approximately $15 \%$ of sporadic cases of $\mathrm{CRC}$, and defines a subset of CRC with unique biology. MSI-H CRC is characterized by exceptionally high mu-

Bever has disclosed that she has no financial interests, arrangements, affiliations, or commercial interests with the manufacturers of any products discussed in this article or their competitors.

Correspondence: Dung T. Le, MD, The Sidney Kimmel Cancer Center, Johns Hopkins University School of Medicine, 1650 Orleans Street, Room 410, Baltimore, MD 21287. E-mail: dle@jhmi.edu 
Bever and Le

tation burden and an immune-active tumor microenvironment with high levels of tumor-infiltrating lymphocytes (TILs) and high levels of expression of multiple immune checkpoints, including PD-1, PDL1, CTLA-4, LAG3, and IDO. ${ }^{9-11}$ Given that these features have been observed in other CPI-responsive cancers, a clinical trial of pembrolizumab in dMMR $\mathrm{mCRC}$ was conducted and demonstrated response rates of $40 \%$ in $\mathrm{dMMR}$ tumors versus no response in proficient MMR (pMMR) tumors. ${ }^{12}$ Updated data from this trial were recently presented, and a response rate of $57 \%$ and disease-control rate of $89 \%$ was seen in $\mathrm{AMMR} C \mathrm{CRC}$ versus $0 \%$ and $16 \%$, respectively, in pMMR CRC. ${ }^{13}$ At a median follow-up of 9.3 months, median disease-free survival and overall survival had not yet been reached in the dMMR cohort, suggesting durable responses in this group. As a result of these observations, pembrolizumab has received breakthrough designation by the FDA for use in MSI-H mCRC.

The activity of nivolumab with or without ipilimumab is also being explored in MSI-H mCRC in the Checkmate-142 trial. ${ }^{14}$ At interim analysis, overall response rates of $25 \%$ and $33 \%$ to monotherapy and the combination, respectively, were reported. Updated results were recently presented of 74 patients treated with nivolumab monotherapy, with an overall response rate of $31 \%$ and disease control rate of $69 \% .^{15}$

CPImonotherapyisbeingfurthertested inMSI-H/ dMMR mCRC in previously treated patients (ClinicalTrials.gov identifier: NCT02460198) and in the first line (NCT02563002). Likely, CPIs will soon enter the standard of care for MSI-H mCRC; however, $>95 \%$ of $\mathrm{mCRC}$ is MSS, and efforts to expand the application of immunotherapy in MSS CRC are ongoing, both through the identification of other potentially susceptible subgroups and through combinatorial approaches.

\section{Other Potential Biomarkers of Response to Immunotherapy in CRC}

A unifying feature of many cancers that respond to CPI therapy is high mutational burden, likely because of the production of neoantigens, which can be detected as foreign by the host. ${ }^{16-18}$ MSI-H CRC exemplifies this, with an exceptionally high mutation burden and high predicted neoantigen load associated with these tumors. A recent large-scale study demonstrated that higher neoantigen load was correlated with increased immune infiltration in the tumor and better survival, even in MSS CRC. ${ }^{19}$ In addition to the MMR proteins classically associated with MSI, other mutations may also lead to a hypermutated phenotype in CRC, including mutations in exonuclease domains of the genes encoding DNA polymerase $\delta$ (POLD1) and $\varepsilon$ (POLE). ${ }^{19-24}$ These data support exploring more broadly the selection of patients with a hypermutated phenotype for treatment with CPI, and, with its increasing availability, next-generation sequencing may have a role.

Extensive efforts to demonstrate the predictive value of PD-L1 expression and response to PD-L1 inhibitors have yielded conflicting results, depending on the tumor type and immunostaining techniques. A meta-analysis of 20 trials involving multiple tumor types demonstrated overall response rates of $34.1 \%$ and $19.9 \%$ in PD-L1-positive and PD-L1negative tumors, respectively. ${ }^{25}$ In CRC, few studies have examined the predictive role of PD-L1. In the aforementioned trial of pembrolizumab in mCRC, although the numbers were small, PD-L1 expression was not significantly associated with progression-free or overall survival. ${ }^{12}$ Preliminary results of another trial of pembrolizumab in PD-L1-expressing tumors demonstrated response in only 1 of 23 patients with PD-L1-positive CRC, and this tumor was found to be MSI-H. ${ }^{26}$ In the aforementioned Checkmate-142 trial, responses were observed regardless of PD-L1 status. ${ }^{15}$ These data suggest a limited role for PD-L1 expression as a biomarker of response in CRC.

Immune infiltration is another potential biomarker of response, as a correlation has been observed between pretreatment CD8-positive T-cell infiltration and response to CPI therapy in melanoma. ${ }^{27}$ Immune infiltrates have been extensively studied in CRC for their role in progression of and prognosis from the disease, ${ }^{28,29}$ and it was demonstrated that the densities and distribution of immune cells in the tumor could outperform the UICC TNM staging system in predicting outcome..$^{30,31}$ The Immunoscore emerged from these studies as a simple tool to stratify CRC tumors through the quantification of densities of 2 lymphocyte populations (CD3/CD45RO or $\mathrm{CD} 3 / \mathrm{CD} 8$ or $\mathrm{CD} 8 / \mathrm{CD} 45 \mathrm{RO}$ ) in the tumor core and at the invasive margin. ${ }^{32,33}$ Immunoscore correlated with extent of disease and survival in these analyses and, strikingly, Mlecnik et $\mathrm{al}^{34}$ demonstrated 
that the Immunoscore was more strongly associated with outcome than was MSI-H status. Proponents of the Immunoscore propose to incorporate it into a standardized staging system for routine clinical use. ${ }^{32}$ The role of Immunoscore in predicting response to CPI therapy has not been tested.

Most recently, gene expression analysis has been used to molecularly characterize and risk-stratify $\mathrm{CRC}$, and has provided further evidence of its diverse biology. Four consensus molecular subtypes (CMS) of CRC based on gene expression profiles have been described: CMS1, "MSI-like" or hypermutated tumors; CMS2, canonical tumors associated with high chromosomal instability and activation of WNT and MYC pathways; CMS3, metabolic tumors associated with KRAS mutations and metabolic dysregulation; and CMS4, mesenchymal tumors. This system demonstrated an ability to stratify tumors by prognosis, with CMS1 tumors unsurprisingly associated with the best prognosis and CMS4 tumors with the worst. It also underscored the limitations of using MSI status alone to stratify patients for treatment, because the CMS1/MSI-H-like group included most but not all MSI-H tumors and some MSS tumors. ${ }^{35}$ Becht et $\mathrm{al}^{36}$ used transcriptomics to characterize the microenvironment of CRC samples with respect to CMS, and observed high expression of immune signatures not only in CMS1 but also in mesenchymal CMS4 CRCs, in which prominent transforming growth factor $\beta$ (TGF- $\beta$ ) activation, stromal invasion, and angiogenesis likely have a large role in tumor immune escape. These data suggest a role for such a classification system in personalized immunotherapy.

\section{Therapeutic Strategies to Enhance Responsiveness to Immunotherapy}

The strategies described may help identify other immunogenic subsets of CRC in which blocking immune checkpoints may be sufficient to yield an effective antitumor immune response. In the remaining poorly immunogenic subsets of CRC, it seems likely that a multipronged approach may be necessary to induce clinically significant responses. To that end, a number of novel immunotherapeutics and combinations are in development to nonspecifically activate the immune system, target the immunosuppressive microenvironment, increase the antigenicity of the tumor, and enhance the antigen-specific immune response (Figure 1).

\section{Other Immunomodulatory Antibodies}

Immune checkpoints serve to downregulate an overactive cytotoxic T-cell response and are exploited by cancer cells. By blocking these molecules at the tumor-immune cell interface, CPIs can thus activate cytotoxic $\mathrm{T}$ cells in a nonspecific manner. The best studied of these are antibodies inhibiting CTLA-4 and the PD-1/PD-L1 interaction. A number of other checkpoints have been identified (eg, LAG3, TIM3, CEACAM, KIR), and antibodies to these targets are currently in development. In addition, cytotoxic

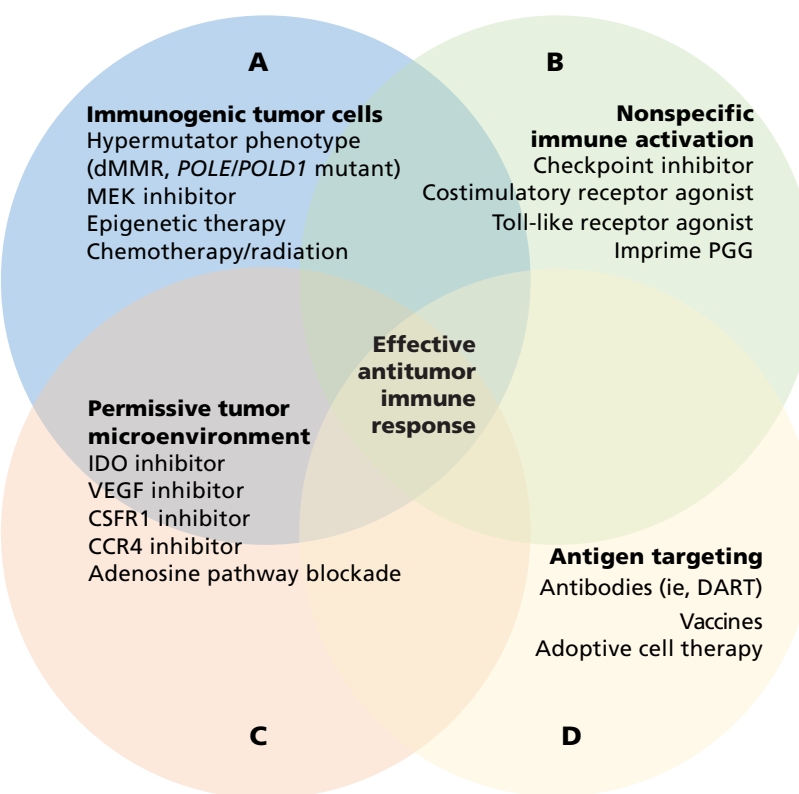

Figure 1. Multipronged approach to optimization of the antitumor immune response. Effective immunotherapeutic strategies must overcome numerous immune evasion strategies active in the tumor, and can broadly be categorized into (B) those which nonspecifically activate immune cells, both through direct action on T-cell receptors and through activation of antigen-presenting cells; (C) tumor antigentargeting therapies, including antitumor antibodies, therapeutic cancer vaccines, and adoptive cell therapies; and (D) drugs which target the immunosuppressive tumor microenvironment, such as those that alter tumor blood supply and lymphocyte trafficking, modify tumor metabolism, and downregulate immunosuppressive regulatory $T$ cells and tumor-associated macrophages. An effective antitumor immune response hinges on $(A)$ the presence of immunogenic tumor cells, which must both produce immunogenic antigens and present them at the cell surface in the context of major histocompatibility complexes. Tumor immunogenicity may be intrinsic to the tumor, as in the case of microsatellite instable colorectal cancer; however, increasing evidence supports the potential for pharmacologic enhancement of tumor immunogenicity.

Abbreviations: DART, dual-affinity retargeting; dMMR, defective mismatch repair; IDO, indoleamine 2,3-dioxygenase; POLD1, DNA polymerase $\delta$; POLE, DNA polymerase $\varepsilon$; VEGF, vascular endothelial growth factor. 
T cells can be activated via costimulatory receptors (eg, OX40, CD40, 41BB, ICOS, CD27, GITR), and antibodies targeting these molecules are being tested as monotherapy or in combination with other CPIs in a number of early-phase trials (Table 1).

Dual CPIs have been observed to increase responses over CPI monotherapy in melanoma, ${ }^{37,38}$ and the aforementioned Checkmate-142 trial in CRC also investigated this strategy in MSS CRC. In a preliminary presentation, objective response was reported in only 1 of 20 patients with MSS CRC. ${ }^{14}$

\section{Activators of the Innate Immune Response}

Toll-like receptors (TLRs) activate the innate immune system in response to pathogen-associated molecular patterns (PAMPs), "danger signals" associated with microbes. A number of TLR agonists are under development and being tested in clinical trials, including a TLR8 agonist with cyclophosphamide in advanced solid tumors (ClinicalTrials. gov identifier: NCT02650635), a TLR5 agonist being tested in the neoadjuvant setting for CRC (NCT02715882), a TLR3 ligand combined with pembrolizumab in mCRC (NCT02834052), and a TLR9 agonist with ipilimumab in advanced malignancies (NCT02668770) and as maintenance therapy after induction in mCRC (NCT02077868).

Imprime PGG is a fungal PAMP used to activate the innate immune system and enhance cytotoxic killing of opsonized cells (ie, epidermal growth factor receptor [EGFR] antibody-treated). A phase II trial in $\mathrm{mCRC}$ in combination with cetuximab showed modest activity, and the combination is being further explored in a phase III trial (ClinicalTrials.gov identifier: NCT01309126). ${ }^{39}$

\section{Tumor Microenvironment-Targeted Agents}

Increasingly, it is understood that tumor cells do not exist in a vacuum, and stromal cells and other features in the tumor microenvironment may contribute significantly to the tumor's ability to escape immune destruction.

Indoleamine 2,3-dioxygenase (IDO) depletes tryptophan in the tumor microenvironment, with a predominant immunosuppressive effect that fa- cilitates tumor immune escape. ${ }^{40}$ IDO inhibitors have been tested in combination with CPIs and cancer vaccines in preclinical models and have shown synergy. ${ }^{41,42}$ Clinical trials are ongoing of IDO inhibitor monotherapy (ClinicalTrials.gov identifier: NCT02048709) and combined with CPIs (NCT02327078, NCT02862457). High IDO expression in CRC correlated with a reduction in CD3positive TILs and was associated with the presence of metastatic disease and outcome, ${ }^{43,44}$ suggesting a role for therapeutic blockade in this disease.

Adenosine is a potent immunosuppressor released in response to cellular stress and has been shown to promote tumor growth and progression through the downregulation of cytotoxic $\mathrm{T}$ cells, recruitment of immunosuppressive cells, and enhanced neovascularization. Inhibition of adenosine production with anti-CD73 antibodies and of adenosine signaling through A2A receptor (A2AR) blockade have been shown to enhance the effectiveness of immunotherapies in preclinical models. ${ }^{45}$ Clinical trials are ongoing to evaluate the use of anti-CD73 antibodies (NCT02754141, NCT02503774) and A2AR blockade (NCT02655822) in combination with the CPIs in advanced cancers, including CRC.

Tumor-associated macrophages of the M2 phenotype are thought to promote tumor growth through the production of proangiogenic and growth factors as well as immunosuppressive cytokines, and M2 macrophages can be depleted with CSF1R inhibitors. A number of clinical trials are investigating the combination of CSF1R inhibitor with PD-L1 blockade (ClinicalTrials.gov identifiers: NCT02777710, NCT02718911, NCT02526017, NCT02829723).

Although not frequently mutated in solid tumors, JAK1 is nonetheless believed to be an important mediator of cell signaling driven by inflammatory cytokines released by tumor cells and the tumor microenvironment, promoting tumorigenesis and metastatic spread and suppression of the antitumor immune response. ${ }^{46}$ In particular, the JAK/ STAT signaling pathway maintains FoxP3 expression on regulatory $\mathrm{T}$ cells (Tregs). ${ }^{47} \mathrm{~A}$ current trial is investigating the combination of pembrolizumab with a JAK1 inhibitor or with PI3K-delta inhibitor (NCT02646748) and in combination with IDO or PI3K-delta inhibitors (NCT02559492).

CCR4 is expressed at high levels on Tregs, and expression of CCR4 ligand represents another mecha- 
Immunotherapy in Colorectal Cancer

Table 1. Select Immunomodulatory Antibodies and Associated Clinical Trials in Solid Tumors Including CRC

\begin{tabular}{|c|c|c|}
\hline Target Molecule & Drug (Company) & Select Clinical Trials Including CRC (ClinicalTrials.gov Identifier) \\
\hline \multirow[t]{2}{*}{ CTLA-4 } & $\begin{array}{l}\text { Ipilimumab } \\
\text { (Bristol-Myers Squibb) }\end{array}$ & $\begin{array}{l}\text { NCT02060188 (+ nivolumab) } \\
\text { NCT01769222 (+ radiation) }\end{array}$ \\
\hline & $\begin{array}{l}\text { Tremelimumab (ticilimumab, CP-675,206) } \\
\text { (Medimmune/AstraZeneca) }\end{array}$ & $\begin{array}{l}\text { NCT02754856 (+ MEDI4736 in resectable mets) } \\
\text { NCT02888743 (+ MEDI4736 + XRT) } \\
\text { NCT02870920 (+ MEDI4736) } \\
\text { NCT01975831 (+ MEDI4736) }\end{array}$ \\
\hline \multirow[t]{3}{*}{ PD-1 } & $\begin{array}{l}\text { Nivolumab } \\
\text { (Bristol-Myers Squibb) }\end{array}$ & $\begin{array}{l}\text { NCT02860546 (+ TAS-102 in MSS aCRC) } \\
\text { NCT02327078 (+ IDO inhibitor) } \\
\text { NCT02423954 (+ chemotherapy) } \\
\text { NCT02636036 (+ enadenotucirev) }\end{array}$ \\
\hline & $\begin{array}{l}\text { Pembrolizumab } \\
\text { (Merck) }\end{array}$ & $\begin{array}{l}\text { NCT01876511 } \\
\text { NCT02460198 (MSI-H/dMMR aCRC) } \\
\text { NCT02563002 (MSI-H/dMMR aCRC first-line) } \\
\text { NCT02713373 (+ cetuximab) } \\
\text { NCT02837263 (+ SBRT in liver mCRC) } \\
\text { NCT02437071 (XRT or ablation) } \\
\text { NCT02375672 (+ mFOLFOX6) } \\
\text { NCT02512172 (+ romidepsin or azacitidine) } \\
\text { NCT02260440 (+ azacitidine) } \\
\text { NCT02851004 (+ stemness inhibitor) } \\
\text { NCT02713529 (+ anti-CSF1R) } \\
\text { NCT02298959 (+ VEGF inhibitor) } \\
\text { NCT02268825 (+ mFOLFOX6) } \\
\text { NCT02318901 (+ cetuximab) } \\
\text { NCT02646748 (+ JAK1 or PIK3-delta inhibitor in MSI CRC) } \\
\text { NCT02178722 (+ IDO inhibitor in MSI CRC) } \\
\text { NCT02856425 (+ VEGF inhibitor) } \\
\text { NCT02834052 (+ TLR3 agonist) }\end{array}$ \\
\hline & $\begin{array}{l}\text { PDR001 } \\
\text { (Novartis) }\end{array}$ & $\begin{array}{l}\text { NCT02678260 } \\
\text { NCT02890069 (+ LCL161, everolimus, or panobinostat) } \\
\text { NCT02900664 (+ immunomodulatory agents) } \\
\text { NCT02829723 (+ CSF1R inhibitor) }\end{array}$ \\
\hline \multirow[t]{3}{*}{ PD-L1 } & $\begin{array}{l}\text { Durvalumab/MEDI4736 } \\
\text { (Medimmune) }\end{array}$ & $\begin{array}{l}\text { NCT02777710 (+ CSF1R inhibitor) } \\
\text { NCT02227667 (in MSI-H or H-TIL CRC) } \\
\text { NCT02484404 (+ VEGF inhibitor in MSS aCRC) } \\
\text { NCT02811497 (+ azacitidine in MSS aCRC) } \\
\text { NCT02586987 (+ MEK inhibitor) }\end{array}$ \\
\hline & $\begin{array}{l}\text { Atezolizumab/MPDL3280A } \\
\text { (Genentech/Roche) }\end{array}$ & $\begin{array}{l}\text { NCT02873195 (+ capecitabine/bevacizumab) } \\
\text { NCT02788279 ( } \pm \text { MEK inhibitor) } \\
\text { NCT02876224 (+ cobimetinib + bevacizumab in MSS aCRC) } \\
\text { NCT02655822 (+ A2AR inhibitor) } \\
\text { NCT01633970 (+ bevacizumab) } \\
\text { NCT01375842 (aCRC) } \\
\text { NCT02912559 (+ FOLFOX in adjuvant for stage III MSI/dMMR CRC) }\end{array}$ \\
\hline & $\begin{array}{l}\text { Avelumab } \\
\text { (Pfizer) }\end{array}$ & $\begin{array}{l}\text { NCT01772004 } \\
\text { NCT02554812 (+ 4-1BB or OX40 agonist) }\end{array}$ \\
\hline \multirow[t]{2}{*}{ LAG-3 } & $\begin{array}{l}\text { BMS-986016 } \\
\text { (Bristol-Myers Squibb) }\end{array}$ & NCT01968109 (alone or + nivolumab) \\
\hline & LAG525 (Novartis) & NCT02460224 ( \pm PDR001) \\
\hline \multirow[t]{2}{*}{ TIM3 } & TSR-022 (Tesaro) & NCT02817633 ( \pm nivolumab) \\
\hline & MBG453 (Novartis) & NCT02608268 ( \pm PDR001) \\
\hline CEACAM1 & CM-24 (cCAM Biotherapeutics) & NCT02346955 ( \pm pembrolizumab) \\
\hline KIR & $\begin{array}{l}\text { BMS-986015 } \\
\text { (Bristol-Myers Squibb) }\end{array}$ & $\begin{array}{l}\text { NCT01750580 (+ ipilimumab) } \\
\text { NCT01714739 (+ nivolumab) }\end{array}$ \\
\hline \multirow[t]{2}{*}{$4-1 B B$} & $\begin{array}{l}\text { Utomilumab/PF-05082566 } \\
\text { (Pfizer) }\end{array}$ & $\begin{array}{l}\text { NCT02554812 (+ avelumab) } \\
\text { NCT02444793 (+ mogamulizumab) } \\
\text { NCT02179918 (+ pembrolizumab) }\end{array}$ \\
\hline & Urelumab/BMS-663513 (BMS) & NCT02253992 (+ nivolumab) \\
\hline \multirow[t]{3}{*}{ OX40 } & MEDI6469 (Medimmune) & NCT02559024 (given before resection of mCRC) \\
\hline & $\begin{array}{l}\text { MEDI0562 } \\
\text { (Medimmune) }\end{array}$ & $\begin{array}{l}\text { NCT02705482 (+ tremelimumab or durvalumab) } \\
\text { NCT02318394 }\end{array}$ \\
\hline & $\begin{array}{l}\text { MOXR0916 } \\
\text { (Genentech) }\end{array}$ & $\begin{array}{l}\text { NCT02219724 } \\
\text { NCT02410512 (+ atezolizumab } \pm \text { bevacizumab }\end{array}$ \\
\hline ICOS & GSK3359609 (GlaxoSmithKline) & NCT02723955 \\
\hline CD27 & $\begin{array}{l}\text { Varlilumab/CDX-1127 } \\
\text { (Celldex Therapeutics) }\end{array}$ & $\begin{array}{l}\text { NCT01460134 } \\
\text { NCT02335918 (+ nivolumab) }\end{array}$ \\
\hline \multirow[t]{8}{*}{ GITR } & $\begin{array}{l}\text { TRX518 } \\
\text { (Leap Therapeutics) }\end{array}$ & $\begin{array}{l}\text { NCT02628574 } \\
\text { NCT01239134 }\end{array}$ \\
\hline & INCAGN01876 (Incyte/Agenus) & NCT02697591 \\
\hline & BMS-986156 (Bristol-Myers Squibb) & NCT02598960 ( \pm nivolumab) \\
\hline & AMG 228 (Amgen) & NCT02437916 \\
\hline & MK-1248 (Merck) & NCT02553499 ( \pm pembrolizumab) \\
\hline & MK-4166 (Merck) & NCT02132754 ( \pm pembrolizumab) \\
\hline & GWN323 (Novartis) & NCT02740270 ( \pm PDR001) \\
\hline & MEDI1873 (Medimmune) & NCT02583165 \\
\hline
\end{tabular}

Abbreviations: A2AR, A2A receptor; aCRC, advanced CRC; CRC, colorectal cancer; dMMR, defective mismatch repair; H-TIL, high levels of tumor infiltrating lymphocytes; IDO, indoleamine 2,3-dioxygenase; mCRC, metastatic CRC; mets, metastasis; MSI, microsatellite instable; MSI-H, microsatellite instability-high; MSS, microsatellite stable; SBRT, stereotactic body radiation therapy; VEGF, vascular endothelial growth factor; XRT, radiotherapy. 
nism of tumor-mediated immune escape. ${ }^{48}$ The CCR 4 ligand CCL17 was observed to induce CRC cell migration, suggesting a role specifically in metastatic spread. ${ }^{49}$ Clinical trials are currently testing this drug alone (ClinicalTrials.gov identifier: NCT02281409), in combination with CPIs (NCT02301130, NCT02705105), or with anti-4-1BB antibody (NCT02444793) in advanced solid tumors.

Treatment with vascular endothelial growth factor (VEGF) inhibitors appears to enhance lymphocyte endothelial trafficking into the tumor and enhances PD-L1 expression, suggesting a role for combination with CPIs. ${ }^{50,51}$ Several such combinations are currently being tested, including bevacizumab plus atezolizumab (ClinicalTrials.gov identifier: NCT01633970), ziv-aflibercept with pembrolizumab (NCT02298959), and a quadruple combination of bevacizumab, durvalumab, tremelimumab, and FOLFOX chemotherapy (NCT02754856).

\section{Enhancement of Tumor Cell Immunogenicity}

Nonspecific activation of the immune system is likely insufficient in poorly immunogenic CRC; however, combination with other therapies that can potentially enhance the immunogenicity of these tumors may be a viable strategy.

A dysfunctional MAPK/ERK pathway is prominent in the pathogenesis of many cancers, including CRC. In preclinical models, treatment with MEK inhibitors increased cytotoxic T-cell infiltration and survival, and increased antigen presentation by tumor cells via class I major histocompatibility complex (MHC) expression, and combination MEK and PD-L1 inhibition appeared to have synergistic effects and induced tumor regression. ${ }^{52}$ Based on this rationale, the MEK inhibitor cobimetinib was combined with the PD-L1 inhibitor atezolizumab in a phase Ib clinical trial (ClinicalTrials.gov identifier: NCT01988896). Interim analysis demonstrated partial responses in 4 of 23 patients with advanced CRC; remarkably, 3 of these responders were documented to be pMMR. Enhanced CD8-positive lymphocyte infiltration and $\mathrm{MHC}$ class I expression were observed in serial biopsies after cobimetinib alone and appeared to be further enhanced by the combination. ${ }^{53}$ This promising data has led to a global phase III study (NCT02788279). Combination co- bimetinib, atezolizumab, and bevacizumab will also be explored in mCRC (NCT02876224).

Epigenetic therapy can induce changes in poorly immunogenic tumors that may sensitize to immunotherapy, likely via effects on tumor cells (ie, increased tumor antigen expression) and host immune cells (enhanced T-cell survival, upregulation of costimulatory receptors, and depletion of myeloid-derived suppressor cells). ${ }^{54-56}$ Preclinical and clinical data suggest a role for combination CPIs with epigenetic therapy, and several clinical trials are evaluating this combination in MSS mCRC (ClinicalTrials.gov identifiers: NCT02811497, NCT02512172), as well as combination epigenetic therapy with a therapeutic cancer vaccine in mCRC (NCT01966289).

Certain chemotherapies, including oxaliplatin, as well as radiation therapy not only work through direct cytotoxic effects but also can generate antitumor immune responses through the induction of a so-called immunogenic cell death and antigenic spread and subsequent activation of antigen-presenting cells. ${ }^{57-59}$ The optimal strategy to capitalize on these effects in combination with immunotherapy is unknown. CPIs are currently being tested in combination with radiation therapy or ablation or chemotherapy in a number of trials in advanced cancer, including CRC (NCT02437071, NCT02843165, NCT02710253, NCT02239900, NCT02423954, NCT02375672, NCT02268825).

\section{Enhancing the Tumor-Specific Immune Response}

\section{Antibodies}

The anti-EGFR monoclonal antibodies cetuximab and panitumumab have been approved for use in RAS wild-type mCRC. Although their activity as monotherapy is modest, combination with CPIs or other immunomodulatory agents may enhance their efficacy and is being explored (ClinicalTrials.gov identifiers: NCT02318901, NCT02713373)..$^{60}$

Dual-affinity retargeting (DART) proteins are bispecific antibody constructs that simultaneously target tumor-associated antigens and T-cell surface proteins, thus recruiting and activating $\mathrm{T}$ cells at the site of the tumor. This construct has shown efficacy in hematologic malignancies. At least 2 DART proteins are currently under development for use in solid tumors: MGD007 (gpA33 x CD3) is a CRC- 
specific drug (NCT02248805), and MGD009 (B7$\mathrm{H} 3 \times \mathrm{CD} 3$ ) is in phase I testing in advanced tumors that express B7-H3 (NCT02628535).

\section{Vaccines}

Cancer vaccines have shown promise in their ability to induce tumor-specific cytotoxic $\mathrm{T}$ cells and humoral responses to tumor antigens; despite this, objective clinical activity has been lim- ited, likely due to the development of T-cell tolerance to self-antigens, which are often the intended targets. Several strategies are currently being explored in CRC, including whole-cell, peptide, dendritic cell, and virus-based vaccines, and several notable CRC vaccines are summarized in Table 2. A meta-analysis of clinical trials of vaccine therapies in CRC published in 2011 demonstrated a benefit in overall survival and dis-

\section{Table 2. Select Vaccine Strategies in CRC}

\begin{tabular}{|c|c|c|c|c|}
\hline Vaccine & Phase & Population & Results & $\begin{array}{l}\text { Ongoing Clinical Trials } \\
\text { (ClinicalTrials.gov } \\
\text { Identifier) }\end{array}$ \\
\hline \multicolumn{5}{|l|}{ Dendritic cell } \\
\hline $\begin{array}{l}\text { MelCancerVac (autologous } \\
\text { mononuclear cells pulsed } \\
\text { with allogeneic tumor cell } \\
\text { lysate) }\end{array}$ & Phase II & Progressive aCRC & $\begin{array}{l}\text { Stable disease achieved in } 4 \text { of } 17 \text { pts treated }(24 \%), \\
\text { associated with increased Th1 cytokines }{ }^{65}\end{array}$ & None \\
\hline $\begin{array}{l}\text { DC/CIK (dendritic cell/ } \\
\text { cytokine-induced killer cell) }\end{array}$ & & Resected gastric/CRC & $\begin{array}{l}54 \text { pts randomized to vaccine vs observation; higher 5-y DFS and } \\
\text { OS in vaccine arm and higher cytokine levels }{ }^{66}\end{array}$ & $\begin{array}{l}\text { NCT01839539 } \\
\text { NCT02415699 }\end{array}$ \\
\hline \multicolumn{5}{|l|}{ Whole cell } \\
\hline $\begin{array}{l}\text { Oncovax (irradiated } \\
\text { autologous cells with BCG } \\
\text { adjuvant) }\end{array}$ & Phase III & $\begin{array}{l}\text { Resectable stage II and } \\
\text { III CRC }\end{array}$ & $\begin{array}{l}\text { Randomized to vaccine vs observation; no significant difference in } \\
\text { DFS or OS }{ }^{67}\end{array}$ & NCT02448173 \\
\hline GVAX (autologous) & Pilot & $\begin{array}{l}\text { Resectable stage IV with } \\
\text { liver mets }\end{array}$ & Ongoing & NCT01952730 \\
\hline GVAX (allogeneic) & Phase I & Stage IV disease & $\begin{array}{l}9 \text { pts ( } 6 \text { resectable, } 3 \text { unresectable) received Cy/GVAX; treatment- } \\
\text { enhanced production of MUC- } 1 \text { atibodies }{ }^{68}\end{array}$ & NCT01966289 \\
\hline $\begin{array}{l}\text { FANG (autologous cancer } \\
\text { cells transfected with GM- } \\
\text { CSF and bi-shRNAi targeting } \\
\text { furin convertase) }\end{array}$ & Phase I & Advanced cancer & $\begin{array}{l}46 \text { pts, } 27 \text { receiving } \geq 1 \text { vaccine, positive ELISPOT correlated with } \\
\text { OS }^{69}\end{array}$ & NCT01505166 \\
\hline \multicolumn{5}{|l|}{ Peptide } \\
\hline Personalized & Phase II & Previously treated aCRC & $\begin{array}{l}60 \text { pts; boosted IgG and CTL responses in } 49 \% \text { and } 63 \% \text {, } \\
\text { respectively, CTL response correlated with OS }\end{array}$ & NCT02600949 \\
\hline $\begin{array}{l}\text { Mutated RAS peptide + } \\
\text { detox-B }\end{array}$ & Pilot, phase I & $\begin{array}{l}\text { Dukes' C CRC after } \\
\text { appropriate adjuvant } \\
\text { chemotherapy; mutant } \\
\text { RAS+ }\end{array}$ & Study completed, no data available & NCT00019006 \\
\hline $\begin{array}{l}\text { EP2101 (10 synthetic peptide } \\
\text { epitopes [2 each from CEA, } \\
\text { p53, HER2/neu, and MAGE } \\
\text { 2/3] plus Montanide ISA } 51 \\
\text { adjuvant) }\end{array}$ & & $\begin{array}{l}\text { Stage IIB/IIIA NSCLC } \\
\text { and stage III CRC who } \\
\text { completed standard } \\
\text { treatment }\end{array}$ & $\begin{array}{l}13 \text { pts treated, } 12 \text { of whom developed vaccine-induced CTL } \\
\text { responses }{ }^{71}\end{array}$ & None \\
\hline \multicolumn{5}{|l|}{ Viral vector } \\
\hline $\begin{array}{l}\text { PANVAC (pox viral vector } \\
\text { encoding MUC-1 and CEA) }\end{array}$ & Phase II & Resected stage IV CRC & $\begin{array}{l}74 \text { pts randomized to DC/PANVAC vs PANVAC/GM-CSF, 2-y RFS } 47 \% \\
\text { and } 55 \% \text {, respectively; superior to historical controls }{ }^{72}\end{array}$ & NCT00088413 \\
\hline $\begin{array}{l}\text { Pexavec/JX } 594 \text { (thymidine } \\
\text { kinase-deactivated vaccinia } \\
\text { virus + GM-CSF) }\end{array}$ & Phase Ib & $\begin{array}{l}\text { Treatment refractory, } \\
\text { measurable CRC }\end{array}$ & 15 pts treated; $10(67 \%)$ with SD at day $29^{73}$ & None \\
\hline MVA vaccine expressing $\mathrm{p} 53$ & Phase I & Refractory GI cancers & $\begin{array}{l}12 \text { pts treated; treatment increased p53-specific CD } 8+\text { T-cell } \\
\text { response after first dose; responses further enhanced with PD-1 } \\
\text { in vitro }{ }^{74}\end{array}$ & NCT02432963 \\
\hline $\begin{array}{l}\text { MVA encoding the tumor } \\
\text { antigen } 5 T 4 \text { (TroVax) }\end{array}$ & Phase I/II & $\mathrm{mCRC}$ & $\begin{array}{l}\text { Several clinical trials demonstrated vaccine-induced cellular and } \\
\text { humoral responses }\end{array}$ & None \\
\hline $\begin{array}{l}\text { Adenoviral Ad-sig-hMUC-1/ } \\
\text { ecdCD40L vector }\end{array}$ & & & & NCT02140996 \\
\hline \multirow[t]{2}{*}{$\begin{array}{l}\text { CEA(6D) VRP vaccine } \\
\text { (AVX701) }\end{array}$} & \multirow[t]{2}{*}{ Phase I } & \multirow[t]{2}{*}{$\begin{array}{l}\text { Select advanced cancers } \\
\text { including CRC }\end{array}$} & $\begin{array}{l}18 \text { pts treated on } 3+3 \text { dose escalation; } 2 \text { pts had SD, } 1 \text { pt with } C R \\
\text { of small liver lesion }\end{array}$ & \multirow[t]{2}{*}{ NCT01890213 } \\
\hline & & & CD4+, CD8+, CEA-specific T-cell and antibody responses observed ${ }^{76}$ & \\
\hline \multicolumn{5}{|l|}{ Other } \\
\hline \multirow{2}{*}{$\begin{array}{l}\text { CDX-1307 (mannose } \\
\text { receptor-targeted } \beta \text {-hCG } \\
\text { vaccine) }\end{array}$} & \multirow[t]{2}{*}{ Phase I } & \multirow{2}{*}{$\begin{array}{l}\text { Select advanced } \\
\text { cancers including CRC; } \\
\text { administered ID or IV, } \\
\text { alone, or with GM-CSF } \pm \\
\text { poly-ICLC or resiquimod } \\
\text { or all agents }\end{array}$} & $\begin{array}{l}89 \text { pts enrolled; hCG-b-specific T-cell responses and antibody } \\
\text { induced to combination + TLR agonist but not to monotherapy }\end{array}$ & \multirow[t]{2}{*}{ None } \\
\hline & & & 9 pts had SD from 2.3 to $18.2 \mathrm{mo}^{77}$ & \\
\hline
\end{tabular}

Abbreviations: aCRC, advanced colorectal cancer; BCG, Bacillus Calmette-Guérin; CEA, carcinoembryonic antigen; CR, complete response; CRC, colorectal cancer; CTL, cytotoxic T lymphocytes; Cy, cyclophosphamide; DC, dendritic cell; DFS, disease-free survival; Gl, gastrointestinal; GM-CSF, granulocyte macrophage colony-stimulating factor; hCG, human chorionic gonadotropin; ID, intradermal; IgG, immunoglobulin G; IV, intravenous; mCRC, metastatic colorectal cancer; mets, metastasis; MVA, modified vaccinia Ankara; NSCLC, non-small cell lung cancer; OS, overall survival; pts, patients; RFS, recurrence-free survival; SD, stable disease; Th1, T helper 1. 
Bever and Le

ease-free survival when used in the adjuvant setting, but little benefit in advanced disease, and accordingly much of the focus in clinical trials has shifted to the adjuvant setting. ${ }^{61}$ However, combinations with CPIs or other immunomodulatory therapy may overcome tolerance mechanisms and yield greater activity. In addition, next-generation sequencing has allowed the prediction of neoantigens and the possibility of manufacturing patientspecific vaccines. ${ }^{62,63}$

\section{Adoptive T-Cell Transfer}

Adoptive T-cell transfer represents another potential strategy to enhance the tumor-specific adaptive immune response. Most promising among the adoptive T-cell transfer strategies is chimeric antigen receptor (CAR) T-cell therapy, in which autologous T cells are engineered to express tumor-specific receptors, allowing for increased specificity and activation on binding. Although CAR T-cell therapy has seen great success in the treatment of lineage restricted hematologic malignancies, its applicability to solid tumors remains to be seen due to a lack of suitable antigen targets. ${ }^{64}$

\section{Summary and Future Directions}

Although previously thought to be a poorly immunogenic cancer, CRC is increasingly understood to be multiple, distinct entities with differing biology and different potential to respond to immunotherapy. Currently, MSI is the only biomarker of response to CPIs, and PD-1-directed therapy may soon become an option for patients with MSI-H CRC. However, other classification systems, such as the Immunoscore and molecular profiling, have shed light on the varying biology of CRC and provide clues that can further increase the ability to predict which patients may benefit from certain immunotherapeutic strategies. Additionally, whole-exome sequencing may have a role in identifying which patients are likely to respond to immunotherapy and identifying potential neoantigens that may serve as the basis for individualized therapies. In most patients, it is likely that combination immunotherapy will be necessary to overcome multiple immune tolerance mechanisms active in these cancers.

\section{References}

1. Siegel RL, Miller KD, Jemal A. Cancer statistics, 2016. CA Cancer J Clin 2016;66:7-30.

2. Jawed I, Wilkerson J, Prasad V, et al. Colorectal cancer survival gains and novel treatment regimens: a systematic review and analysis. JAMA Oncol 2015;1:787-795.

3. American Cancer Society. Colorectal Cancer Facts and Figures 2014-2016. Available at: https://www.cancer.org/content/dam/cancer-org/research/ cancer-facts-and-statistics/colorectal-cancer-facts-and-figures/colorectalcancer-facts-and-figures-2014-2016.pdf. Accessed February 13, 2017.

4. Grothey A, Van Cutsem E, Sobrero A, et al. Regorafenib monotherapy for previously treated metastatic colorectal cancer (CORRECT): an international, multicentre, randomised, placebo-controlled, phase 3 trial. Lancet 2013;381:303-312.

5. Longo-Munoz F, Argiles G, Tabernero J, et al. Efficacy of trifluridine and tipiracil (TAS-102) versus placebo, with supportive care, in a randomized, controlled trial of patients with metastatic colorectal cancer from Spain: results of a subgroup analysis of the phase 3 RECOURSE trial. Clin Transl Oncol 2017;19:227-235.

6. Brahmer JR, Tykodi SS, Chow LQ, et al. Safety and activity of anti-PD-L1 antibody in patients with advanced cancer. N Engl J Med 2012;366:24552465.

7. Brahmer JR, Drake CG, Wollner I, et al. Phase I study of single-agent anti-programmed death-1 (MDX-1106) in refractory solid tumors: safety, clinical activity, pharmacodynamics, and immunologic correlates. J Clin Oncol 2010;28:3167-3175.

8. Topalian SL, Hodi FS, Brahmer JR, et al. Safety, activity, and immune correlates of anti-PD-1 antibody in cancer. N Engl J Med 2012;366:24432454.

9. Smyrk TC, Watson P, Kaul K, Lynch HT. Tumor-infiltrating lymphocytes are a marker for microsatellite instability in colorectal carcinoma. Cancer 2001;91:2417-2422.

10. Rosenbaum MW, Bledsoe JR, Morales-Oyarvide V, et al. PD-L1 expression in colorectal cancer is associated with microsatellite instability, BRAF

mutation, medullary morphology and cytotoxic tumor-infiltrating lymphocytes. Mod Pathol 2016;29:1104-1112.

11. Llosa NJ, Cruise M, Tam A, et al. The vigorous immune microenvironment of microsatellite instable colon cancer is balanced by multiple counter inhibitory checkpoints. Cancer Discov 2015;5:43-51.

12. Le DT, Uram JN, Wang H, et al. PD-1 blockade in tumors with mismatchrepair deficiency. N Engl J Med 2015;372:2509-2520.

13. Le DT, Uram JN, Wang $\mathrm{H}$, et al. Programmed death-1 blockade in mismatch repair deficient colorectal cancer [abstract]. J Clin Oncol 2016;34(Suppl):Abstract 103.

14. Overman MJ, Kopetz S, McDermott RS, et al. Nivolumab +/- ipilimumab in treatment of patients with metastatic colorectal cancer with and without high microsatellite instability: CheckMate-142 interim results [abstract]. ] Clin Oncol 2016;34(Suppl):Abstract 3501.

15. Overman MJ, Lonardi S, Leone F, et al. Nivolumab in patients with DNA mismatch repair deficient/microsatellite instability high metastatic colorectal cancer: update from CheckMate 142 [abstract]. J Clin Oncol 2017;35(Suppl):Abstract 519.

16. Rizvi NA, Hellmann MD, Snyder A, et al. Cancer immunology. Mutational landscape determines sensitivity to PD-1 blockade in non-small cell lung cancer. Science 2015;348:124-128.

17. Snyder A, Makarov V, Merghoub T, et al. Genetic basis for clinical response to CTLA-4 blockade in melanoma. N Engl J Med 2014;371:2189-2199.

18. Van Allen EM, Miao D, Schilling B, et al. Genomic correlates of response to CTLA-4 blockade in metastatic melanoma. Science 2015;350:207-211.

19. Giannakis M, Mu XJ, Shukla SA, et al. Genomic correlates of immune-cell infiltrates in colorectal carcinoma. Cell Rep 2016;17:1206.

20. Kothari N, Teer JK, Abbott AM, et al. Increased incidence of FBXW7 and POLE proofreading domain mutations in young adult colorectal cancers. Cancer 2016;122:2828-2835.

21. Ahn SM, Ansari AA, Kim J, et al. The somatic POLE P286R mutation defines a unique subclass of colorectal cancer featuring hypermutation, representing a potential genomic biomarker for immunotherapy. Oncotarget 2016;7:68638-68649. 
22. Cancer Genome Atlas Network. Comprehensive molecular characterization of human colon and rectal cancer. Nature 2012;487:330-337.

23. Howitt BE, Shukla SA, Sholl LM, et al. Association of polymerase e-mutated and microsatellite-instable endometrial cancers with neoantigen load, number of tumor-infiltrating lymphocytes, and expression of PD-1 and PD-L1. JAMA Oncol 2015;1:1319-1323.

24. Nicolas E, Golemis EA, Arora S. POLD1: central mediator of DNA replication and repair, and implication in cancer and other pathologies. Gene 2016;590:128-141.

25. Carbognin L, Pilotto S, Milella M, et al. Differential activity of nivolumab, pembrolizumab and MPDL3280A according to the tumor expression of programmed death-ligand-1 (PD-L1): sensitivity analysis of trials in melanoma, lung and genitourinary cancers. PLoS One 2015;10:e0130142.

26. O’Neil B, Wallmark J, Lorente D, et al. Pembrolizumab (MK-3475) for patients with advanced colorectal carcinoma: preliminary results from KEYNOTE-028 [abstract]. Eur J Cancer 2016;51(Suppl):Abstract 502

27. Tumeh PC, Harview CL, Yearley JH, et al. PD-1 blockade induces responses by inhibiting adaptive immune resistance. Nature 2014;515:568-571.

28. Naito $Y$, Saito K, Shiiba K, et al. CD8+ T cells infiltrated within cancer cell nests as a prognostic factor in human colorectal cancer. Cancer Res 1998;58:3491-3494.

29. Pages F, Berger A, Camus M, et al. Effector memory $T$ cells, early metastasis, and survival in colorectal cancer. N Engl J Med 2005;353:2654-2666.

30. Galon J, Costes A, Sanchez-Cabo F, et al. Type, density, and location of immune cells within human colorectal tumors predict clinical outcome. Science 2006;313:1960-1964.

31. Mlecnik B, Tosolini M, Kirilovsky A, et al. Histopathologic-based prognostic factors of colorectal cancers are associated with the state of the local immune reaction. J Clin Oncol 2011;29:610-618.

32. Galon J, Mlecnik B, Bindea G, et al. Towards the introduction of the 'Immunoscore' in the classification of malignant tumours. J Pathol 2014;232:199-209.

33. Pages F, Kirilovsky A, Mlecnik B, et al. In situ cytotoxic and memory T cells predict outcome in patients with early-stage colorectal cancer. J Clin Oncol 2009;27:5944-5951.

34. Mlecnik B, Bindea G, Angell HK, et al. Integrative analyses of colorectal cancer show immunoscore is a stronger predictor of patient survival than microsatellite instability. Immunity 2016;44:698-711.

35. Guinney J, Dienstmann R, Wang X, et al. The consensus molecular subtypes of colorectal cancer. Nat Med 2015;21:1350-1356.

36. Becht E, de Reynies A, Giraldo NA, et al. Immune and stromal classification of colorectal cancer is associated with molecular subtypes and relevant for precision immunotherapy. Clin Cancer Res 2016;22:4057-4066.

37. Larkin J, Chiarion-Sileni V, Gonzalez R, et al. Combined nivolumab and ipilimumab or monotherapy in untreated melanoma. N Engl J Med 2015;373:23-34.

38. Postow MA, Chesney J, Pavlick AC, et al. Nivolumab and ipilimumab versus ipilimumab in untreated melanoma. N Engl J Med 2015;372:20062017

39. Segal NH, Gada P, Senzer N, et al. A phase II efficacy and safety, openlabel, multicenter study of imprime PGG injection in combination with cetuximab in patients with stage IV KRAS-mutant colorectal cancer. Clin Colorectal Cancer 2016;15:222-227.

40. Lob S, Konigsrainer A, Rammensee HG, et al. Inhibitors of indoleamine2,3-dioxygenase for cancer therapy: can we see the wood for the trees? Nat Rev Cancer 2009;9:445-452.

41. Spranger S, Koblish HK, Horton B, et al. Mechanism of tumor rejection with doublets of CTLA-4, PD-1/PD-L1, or IDO blockade involves restored IL-2 production and proliferation of CD $8(+) \mathrm{T}$ cells directly within the tumor microenvironment. J Immunother Cancer 2014;2:3.

42. Uyttenhove C, Pilotte L, Theate I, et al. Evidence for a tumoral immune resistance mechanism based on tryptophan degradation by indoleamine 2,3-dioxygenase. Nat Med 2003;9:1269-1274.

43. Brandacher G, Perathoner A, Ladurner R, et al. Prognostic value of indoleamine 2,3-dioxygenase expression in colorectal cancer: effect on tumor-infiltrating T cells. Clin Cancer Res 2006;12:1144-1151.

44. Ferdinande L, Decaestecker C, Verset L, et al. Clinicopathological significance of indoleamine 2,3-dioxygenase 1 expression in colorecta cancer. Br J Cancer 2012;106:141-147.

45. Young A, Ngiow SF, Barkauskas DS, et al. Co-inhibition of CD73 and A2AR adenosine signaling improves anti-tumor immune responses. Cancer Cell 2016;30:391-403.

46. Buchert M, Burns CJ, Ernst M. Targeting JAK kinase in solid tumors: emerging opportunities and challenges. Oncogene 2016;35:939-951.
47. Passerini L, Allan SE, Battaglia M, et al. STAT5-signaling cytokines regulate the expression of FOXP3 in CD4+CD25+ regulatory $\mathrm{T}$ cells and CD4+CD25- effector T cells. Int Immunol 2008;20:421-431.

48. Chang DK, Peterson E, Sun J, et al. Anti-CCR4 monoclonal antibody enhances antitumor immunity by modulating tumor-infiltrating Tregs in an ovarian cancer xenograft humanized mouse model. Oncoimmunology 2016;5:e1090075.

49. Al-haidari AA, Syk I, Jirstrom K, Thorlacius H. CCR4 mediates CCL17 (TARC)-induced migration of human colon cancer cells via RhoA/Rhokinase signaling. Int J Colorectal Dis 2013;28:1479-1487.

50. Wu X, Giobbie-Hurder A, Liao X, et al. VEGF neutralization plus CTLA4 blockade alters soluble and cellular factors associated with enhancing lymphocyte infiltration and humoral recognition in melanoma. Cancer Immunol Res 2016;4:858-868.

51. Liu XD, Hoang A, Zhou L, et al. Resistance to antiangiogenic therapy is associated with an immunosuppressive tumor microenvironment in metastatic renal cell carcinoma. Cancer Immunol Res 2015;3:1017-1029.

52. Ebert PJ, Cheung J, Yang Y, et al. MAP kinase inhibition promotes T cell and anti-tumor activity in combination with PD-L1 checkpoint blockade. Immunity 2016;44:609-621.

53. Bendell JC, Kim TW, Goh BC, et al. Clinical activity and safety of cobimetinib (cobi) and atezolizumab in colorectal cancer (CRC) [abstract]. J Clin Oncol 2016;34(Suppl):Abstract 3502.

54. Kim K, Skora AD, Li Z, et al. Eradication of metastatic mouse cancers resistant to immune checkpoint blockade by suppression of myeloidderived cells. Proc Natl Acad Sci U S A 2014;111:11774-11779.

55. Chiappinelli KB, Zahnow CA, Ahuja N, Baylin SB. Combining epigenetic and immunotherapy to combat cancer. Cancer Res 2016;76:1683-1689.

56. Wrangle J, Wang W, Koch A, et al. Alterations of immune response of nonsmall cell lung cancer with azacytidine. Oncotarget 2013;4:2067-2079.

57. Herrera FG, Bourhis J, Coukos G. Radiotherapy combination opportunities leveraging immunity for the next oncology practice. CA Cancer J Clin 2017;67:65-85.

58. Tesniere A, Schlemmer F, Boige V, et al. Immunogenic death of colon cancer cells treated with oxaliplatin. Oncogene 2010;29:482-491.

59. Zitvogel L, Apetoh L, Ghiringhelli F, Kroemer G. Immunological aspects of cancer chemotherapy. Nat Rev Immunol 2008;8:59-73.

60. Kohrt HE, Colevas AD, Houot R, et al. Targeting CD137 enhances the efficacy of cetuximab. J Clin Invest 2014;124:2668-2682.

61. Rao B, Han M, Wang L, et al. Clinical outcomes of active specific immunotherapy in advanced colorectal cancer and suspected minimal residual colorectal cancer: a meta-analysis and system review. J Transl Med 2011;9:17.

62. Schumacher TN, Schreiber RD. Neoantigens in cancer immunotherapy. Science. 2015;348:69-74.

63. Zhang X, Sharma PK, Peter Goedegebuure S, Gillanders WE. Personalized cancer vaccines: targeting the cancer mutanome. Vaccine 2017;35:10941100 .

64. Abken $\mathrm{H}$. Adoptive therapy with $\mathrm{CAR}$ redirected $\mathrm{T}$ cells: the challenges in targeting solid tumors. Immunotherapy 2015;7:535-544.

65. Burgdorf SK. Dendritic cell vaccination of patients with metastatic colorectal cancer. Dan Med Bull 2010;57:B4171.

66. Gao D, Li C, Xie X, et al. Autologous tumor lysate-pulsed dendritic cell immunotherapy with cytokine-induced killer cells improves survival in gastric and colorectal cancer patients. PLoS One 2014;9:e93886.

67. Uyl-de Groot CA, Vermorken JB, Hanna MG Jr, et al. Immunotherapy with autologous tumor cell-BCG vaccine in patients with colon cancer: a prospective study of medical and economic benefits. Vaccine 2005;23:2379-2387.

68. Zheng L, Edil BH, Soares KC, et al. A safety and feasibility study of an allogeneic colon cancer cell vaccine administered with a granulocytemacrophage colony stimulating factor-producing bystander cell line in patients with metastatic colorectal cancer. Ann Surg Oncol 2014;21:39313937.

69. Senzer N, Barve M, Kuhn J, et al. Phase I trial of "bi-shRNAi(furin)/ GMCSF DNA/autologous tumor cell" vaccine (FANG) in advanced cancer. Mol Ther 2012;20:679-686.

70. Kibe S, Yutani S, Motoyama S, et al. Phase II study of personalized peptide vaccination for previously treated advanced colorectal cancer. Cancer Immunol Res 2014;2:1154-1162.

71. Ishioka GY, Disis ML, Morse MA, et al. A phase I trial of a multi-epitope cancer vaccine (EP-2101) in non-small cell lung (NSCLC) and colon cancer patients [abstract]. J Clin Oncol 2004;22(14 Suppl):Abstract 2525. 


\section{Bever and Le}

72. Morse MA, Niedzwiecki D, Marshall JL, et al. A randomized phase II study of immunization with dendritic cells modified with poxvectors encoding CEA and MUC1 compared with the same poxvectors plus GM-CSF for resected metastatic colorectal cancer. Ann Surg 2013;258:879-886.

73. Park SH, Breitbach CJ, Lee J, et al. Phase $1 \mathrm{~b}$ trial of biweekly intravenous Pexa-Vec (JX-594), an oncolytic and immunotherapeutic vaccinia virus in colorectal cancer. Mol Ther 2015;23:1532-1540.

74. Hardwick NR, Carroll M, Kaltcheva T, et al. p53MVA therapy in patients with refractory gastrointestinal malignancies elevates p53-specific CD8+ T-cell responses. Clin Cancer Res 2014;20:4459-4470.
75. Rowe J, Cen P. TroVax in colorectal cancer. Hum Vaccin Immunother 2014;10:3196-3200.

76. Morse MA, Hobeika AC, Osada T, et al. An alphavirus vector overcomes the presence of neutralizing antibodies and elevated numbers of Tregs to induce immune responses in humans with advanced cancer. J Clin Invest 2010;120:3234-3241.

77. Morse MA, Chapman R, Powderly J, et al. Phase I study utilizing a novel antigen-presenting cell-targeted vaccine with Toll-like receptor stimulation to induce immunity to self-antigens in cancer patients. Clin Cancer Res 2011;17:4844-4853. 